\title{
STUDY OF THE PLACENTAL ATTACHMENT OF FUNICULUS UMBILICALIS IN NORMAL AND PRE-ECLAM PTIC PREGNANCIES AND ITS EFFECTS ON BIRTH WEIGHT
}

\author{
Ankit Jain ${ }^{* 1}$, Sonia Baweja ${ }^{2}$, Rashmi Jain ${ }^{3}$.
}

${ }^{* 1}$ M.S., Ex. Resident, Department of Anatomy, Gandhi M edical College, Bhopal (M .P.), India.

2 M.S., Associate Professor, Department of Anatomy, Gandhi M edical College, Bhopal (M .P.), India.

${ }^{3}$ M .D., Lab Head, Consultant Pathologist, SRL Diagnostics Ltd, Malviya Nagar, Bhopal (M .P.), India.

\section{ABSTRACT}

Introduction: Abnormalities in the insertion of umbilical cord is associated with a number of complications in pregnancy and these complications may adversely affect the fetus. The aim of this study was to evaluate the variations in the attachment of umbilical cord in normal and pre-eclamptic pregnancies and to assess the effects of variable cord insertions on fetal birth weight.

Materials and M ethods: Seventy placentae each of normotensive and pre-eclamptic pregnancies were studied $(n=140)$. After delivery, weight of the baby was recorded by using weighing machine and the attachment of umbilical cord on placenta was observed.

Results: In the present study, commonest site of insertion of umbilical cord was central (60\%) in normal pregnancies, whereas in pre-eclamptic pregnancies, a common site of insertions of umbilical cord were central (37.14\%) and/or eccentric (34.28\%). Marginal cord insertions were found 2.11 times more in pre-eclamptic pregnancies as compared to normal pregnancies. A single case of velamentous insertion was found in the preeclamptic pregnancies. We found that $65.52 \%$ of placentae with abnormal cord insertions were associated with low fetal birth weight and the association between cord insertion and fetal birth weight was found statistically highly significant.

Discussion: Abnormal cord insertions are significantly associated with pre-eclampsia. Mean fetal birth weight decreases as the site of cord insertion moves towards the periphery. Conclusively, abnormalities in the site of insertion of umbilical cord have an adverse effect on fetal health. Therefore, early detection of abnormal cord insertion may provide sufficient information to take additional care in such conditions.

KEY WORDS: Birth weight, Cord insertion, Pre-eclampsia, Placenta, Umbilical cord.

Address for Correspondence: Dr. Ankit Jain, S/O Subodh Kumar Jain, Near Jain mandir, Neha Nagar (Shakti Nagar), Makronia, distt. SAGAR, (M .P.), Pin- 470004,

Telephone: +91 9827570908, +91 9977799776. E-Mail: ankitjain6285@gmail.com

\begin{tabular}{|l|l|}
\multicolumn{3}{|c|}{ Access this Article online } \\
\hline Quick Response code & $\begin{array}{l}\text { Web site: International Journal of Anatomy and Research } \\
\text { ISSN 2321-4287 } \\
\text { www.ijmhr.org/ijar.htm }\end{array}$ \\
\cline { 2 - 3 } & \multicolumn{2}{|c|}{$\begin{array}{l}\text { Accepted: 13 Feb } 2017 \\
\text { Dol: } 10.16965 / \text { ijar.2017.107 }\end{array}$} & $\begin{array}{l}\text { Received: 06 Jan 2017 } \\
\text { Peer Review: 06 Jan 2017 }\end{array}$ & $\begin{array}{l}\text { Published (O): 28 Feb } 2017 \\
\text { Revised: None }\end{array}$ & Published (P): 28 Feb 2017 \\
\hline
\end{tabular}

\section{INTRODUCTION}

The umbilical cord is also referred to as Funiculus umbilicalis or Birth cord. It is a flexible structure that connects the developing embryo to the fetal surface of the placenta [1]. The umbilical cord delivers oxygen and nutrients to the developing fetus throughout pregnancy. Thus, the growth of the fetus is highly dependent on the 
development of the umbilical cord [2]. Normally, the umbilical cord is inserted at the center or near the center (eccentric) of the placenta. Other types of attachments of umbilical cords are marginal, velamentous and furcated [3]. In marginal cord insertion, the umbilical cord is inserted within $2 \mathrm{~cm}$ from the placental edge [4]. In velamentous cord insertion, the umbilical cord is inserted into the chorio-amniotic membranes rather than on to the placental mass [5]. In furcated insertion, umbilical cord branch before its insertion on the fetal surface of the placenta [6]. Variations in the site of insertion of umbilical cords are explained by two different theories. First is "placental migration theory or trophotropism", in which the placenta migrates towards the richly vascularised area with advancing gestation to achieve better perfusion [7]. Another is the "blastocyst polarity theory", which hypothesizes that abnormal cord insertion results from malpositioning of blastocyst during implantation [8].

Abnormal cord insertion is associated with poor obstetric outcomes. Increased rates of fetal malformation, low birth weight, preterm labor, fetal growth restriction, vasa previa, low APGAR (appearance, pulse, grimace, activity and respiratory rate) scores and intrapartum complications have been noted with velamentous cord insertions $[7,9,10]$. In velamentous cord insertion, umbilical vessels are inserted into the membranes, therefore these vessels lack the protection of Wharton's jelly and are prone to rupture and/or compression, which results in acute cessation of umbilical blood flow. Thus the risk of perinatal death is increased in pregnancies with velamentous cord insertions [11]. Various studies suggest that compression of umbilical vessels reduces cardiac output and increases the risk of pulmonary complications after birth [12, 13]. Marginal cord insertion has also been associated with fetal growth restriction and preterm delivery $[9,14]$. Because of poor obstetric outcomes, evaluation of the attachment of umbilical cord deserves attention right from the first trimester. Sonographic visualization of the site of cord insertion becomes more difficult with advancing gestation; therefore, it should be evaluated at 15-20 weeks of gestation $[15,16]$.
The purpose of this study was to observe the variations in the attachment of umbilical cord in normal and pre-eclamptic pregnancies and to determine whether the umbilical cord insertion site could be linked to fetal birth weight.

\section{MATERIALS AND METHODS}

The present study was an observational comparative study, which was carried out in the Department of Anatomy, Gandhi Medical College, Bhopal (M.P). A total of 140 placentae with umbilical cord were collected from pregnant women delivered in Sultania Zanana Hospital associated to G.M.C. Bhopal, after permission from institutional ethics committee. All mothers were properly explained about the study and their written consent was taken. Women were diagnosed with pre-eclampsia if they had systolic BP $\geq 140 \mathrm{mmHg}$ and diastolic $\mathrm{BP} \geq 90 \mathrm{mmHg}$ measured on two or more occasions, at least 4 hrs apart after the 20th week of gestation with proteinuria. Proteinuria was considered when there was a urine dipstick value of at least $1+(>30 \mathrm{mg} / \mathrm{dl})$ on two separate occasions at least 6 hours apart [17]. On this basis, subjects were divided into two groups. Group I consist of placentae obtained from normal pregnant women $(n=70)$ with gestational age 37-40 weeks. Group II consist of placentae obtained from pre-eclamptic women $(n=70)$ of similar gestational age. Patients with essential hypertension, diabetes mellitus, anemia, renal disorders and other illness associated with pregnancy were excluded from this study.

The mother's and their neonates identified for this study were given code numbers and studied at the hospital. After delivery, fetal birth weight was recorded. The placentae were collected soon after their expulsion and washed in the running tap water to clear all blood. Distance from the placental margin to the site of attachment of the umbilical cord was measured. The attachment of the umbilical cord on the fetal surface of the placenta was categorized into central, eccentric, marginal and velamentous insertion. Central cord insertion includes the cord, which was inserted into the center of placenta, whereas cords which were inserted near the center were included in eccentric cord insertion. Both central and eccen- 
tric cord insertions were considered as normal cord insertion [Fig. 1A, B]. M arginal cord insertion includes the cord, which was inserted within $2 \mathrm{~cm}$ from placental margin, whereas velamentous cord insertion includes the cord which was inserted into the membrane rather than placental mass. Both marginal and velamentous cord insertions, were considered as abnormal cord insertion [Fig. 2A, B].

Statistical analysis of data was performed by using Statistical Package for Social Sciences (SPSS) version 15.0 (Chicago, IL). The values of continuous variables were presented as mean values \pm standard deviation. The statistical significance was analyzed by using Chi-square test for categorical data. The significance of differences between group parameters was considered significant if $p<0.05$.

Fig. 1: Showing placenta with normal umbilical cord (UC) insertion taken from normal pregnancy. A. Showing central cord insertion in which umbilical cord (UC) inserted in the center $(\mathrm{Cr})$ of the placenta. B. Showing eccentric cord insertion in which umbilical cord (UC) inserted near the center $(\mathrm{Cr})$ of the placenta.

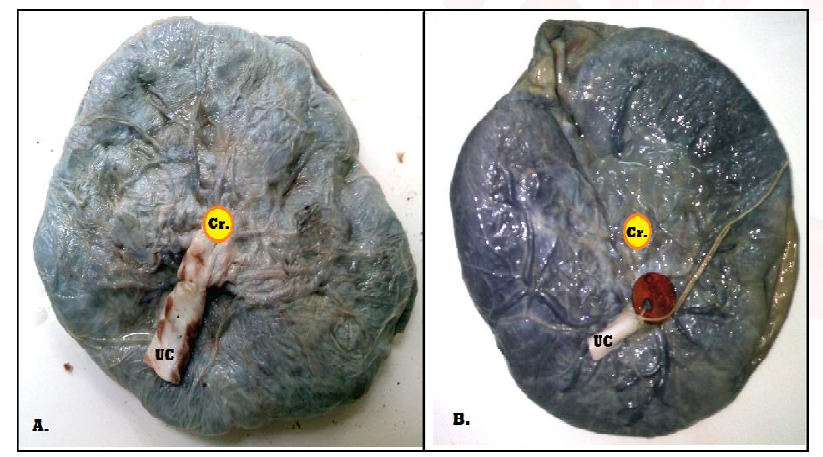

Fig. 2: Showing placenta with abnormal umbilical cord (UC) insertion taken from pre-eclamptic pregnancy. A. Showing marginal cord insertion in which umbilical cord (UC) inserted within $2 \mathrm{~cm}$ from the placental edge. B. Showing velamentous cord insertion in which umbilical cord (UC), inserted in the membrane (arrow).

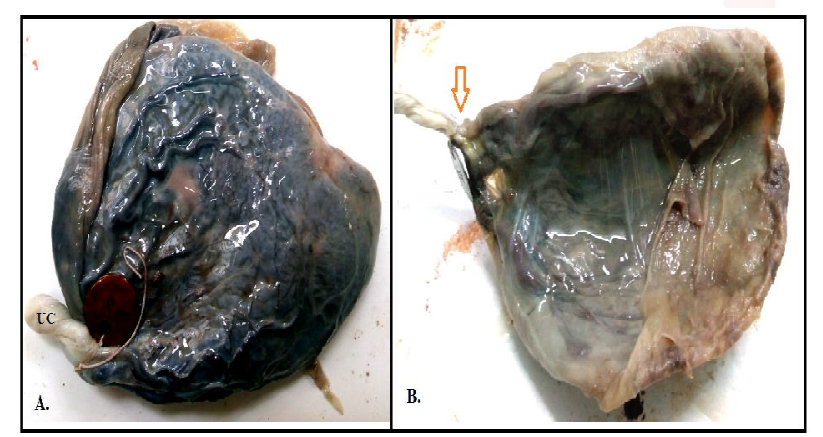

\section{RESULTS}

In the present study, central cord insertion was found in $60 \%$ and eccentric cord insertion was found in $27.14 \%$ placentae of normal pregnancies. In pre-eclamptic pregnancies, central and eccentric cord insertions were found in $37.14 \%$ and $34.28 \%$ placentae respectively. Marginal cord insertion was found in $12.86 \%$ and $27.14 \%$ placentae of normal and pre-eclamptic pregnancies respectively. Only one case of velamentous insertion was found in the pre-eclamptic pregnancies. Thus the commonest site of insertion of the umbilical cord in normal pregnancy was central, whereas in pre-eclamptic pregnancies commonest sites of insertion of umbilical cord were central and/or eccentric. We observed that marginal cord insertions were 2.11 times more in pre-eclamptic pregnancies as compared to normal pregnancies. Statistically, the differences in the attachment of umbilical cord between two groups were found to be significant [Table-1].

Table 1: Distribution of the insertion of umbilical cord in normal and pre-eclamptic pregnancies.

\begin{tabular}{|c|c|c|}
\hline Type of insertion & $\begin{array}{c}\text { Control group } \\
(\mathbf{n}=70)\end{array}$ & $\begin{array}{c}\text { Pre-eclamptic } \\
\text { group }(\mathrm{n}=70)\end{array}$ \\
\hline Central & $42(60 \%)$ & $26(37.14 \%)$ \\
\hline Ec-centric & $19(27.14 \%)$ & $24(34.28 \%)$ \\
\hline Marginal & $9(12.86 \%)$ & $19(27.14 \%)$ \\
\hline Velamentous & 0 & $1(1.43 \%)$ \\
\hline Total & $70(100 \%)$ & $70(100 \%)$ \\
\hline
\end{tabular}

Chi-square $\left(x^{2}\right)=8.917, \mathrm{df}=3, p=0.03$, Statistically significant.

Fig. 3: Comparison of mean fetal birth weight in various cord insertions.

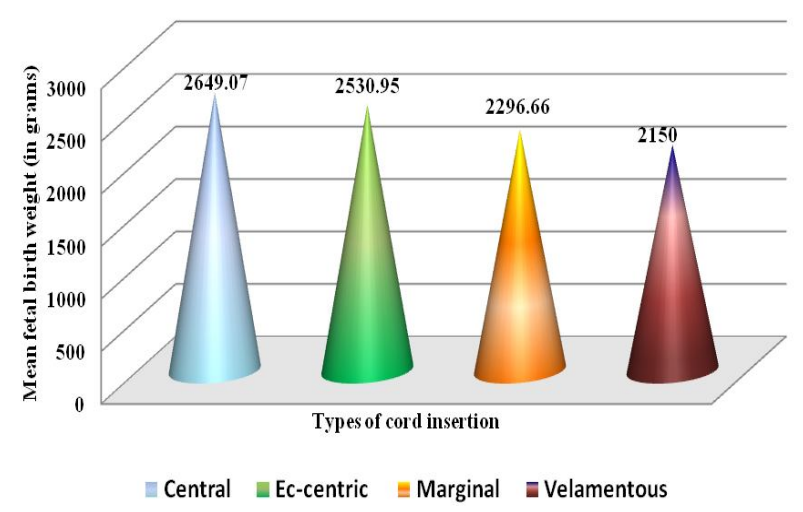

In our study, mean fetal birth weight was found $2649.07 \pm 260.52$ grams and $2530.95 \pm 215.49$ grams in placentae with central and eccentric cord insertion respectively. Whereas in placentae with marginal and velamentous cord insertion, mean fetal birth weight was found 2296.66 \pm 273.77 grams and 2150 grams respectively [Fig. $3]$. We also observed that $65.52 \%$ of placentae with abnormal cord insertions were associated 
with low fetal birth weight (birth weight less than 2500 grams), while $72.07 \%$ of placentae with normal cord insertions were associated with fetal birth weight more than 2500 grams. The relation between umbilical cord insertion on the placenta and fetal birth weight were found statistically highly significant [Table-2].

Table 2: Relation between umbilical cord insertion and fetal birth weight.

\begin{tabular}{|c|c|c|c|}
\hline \multirow{2}{*}{ Type of insertion } & \multicolumn{2}{|c|}{$\begin{array}{c}\text { Fetal birth weight } \\
\text { (in grams) }\end{array}$} & \multirow{2}{*}{$\begin{array}{c}\text { Total } \\
\text { ( } \mathbf{n = 1 4 0 )}\end{array}$} \\
\cline { 2 - 3 } & $\mathbf{2 5 0 0}$ & $>\mathbf{2 5 0 0}$ & \\
\hline $\begin{array}{c}\text { Normal cord } \\
\text { insertion* }\end{array}$ & $31(27.93 \%)$ & $80(72.07 \%)$ & $111(100 \%)$ \\
\hline $\begin{array}{c}\text { Abnormal cord } \\
\text { insertion** }\end{array}$ & $19(65.52 \%)$ & $10(34.48 \%)$ & $\begin{array}{c}29 \\
(100 \%)\end{array}$ \\
\hline
\end{tabular}

Chi-square $\left(x^{2}\right)=14.973, d f=1, p=0.0001$, Statistically highly significant.

* Normal cord insertion includes centric and ec-centric cord insertions.

** Abnormal cord insertion includes marginal and velamentous cord insertions.

\section{DISCUSSION}

Udainia A. et al., reported that commonest site of the insertion of the umbilical cord is eccentric in both normal and pre-eclamptic pregnancies [18]. In contrast to above, present study showed that the commonest site of insertion of the umbilical cord was central in normal pregnancies, whereas, in pre-eclamptic pregnancies, central and eccentric insertion were found in almost equal proportion [Table-1]. In our study, the attachment of umbilical cord was found to be normal (central/eccentric) in $87.14 \%$ placentae of uncomplicated pregnancies. This finding is consistent with those reported by earlier observers [19-22] in a manner that central and/ or eccentric cord insertions were the commonest type of attachment of the umbilical cord on placenta in uncomplicated pregnancies [Tab-3]. Therefore, these types of cord attachments were considered as normal cord insertions.

Previous experience of caesarean delivery and maternal medical conditions i.e. maternal asthma, gestational diabetes, chronic hypertension had an increased risk of abnormal cord insertion [11]. Udainia A. et al., found that as the severity of pregnancy induced hypertension increases, insertion of the umbilical cord becomes marginal to velamentous in nature [18].
Benirschke K. found that incidence of marginal cord insertion was $7.9 \%$ in singletons and $24.33 \%$ in twins [23], whereas Ebbing $C$. et al, found the incidence of marginal cord insertion was $6.3 \%$ in singletons and $10.9 \%$ in twins [11]. Although all subjects in our study were singletons. In this study, the incidence of marginal cord insertion was found in $12.86 \%$ placentae of normal singletons pregnancies [Table-1 \& 3], which is higher as compared to above-mentioned studies, but is lower to the study done by Di Salvo et al [22], and Lakshmidevi CK. et al [19] [Table-3]. Rath $G$. et al, reported that marginal cord insertion is associated with hypertensive pregnancies [24]. In the present study, we found that prevalence of marginal cord insertions was 2.11 times more in pre-eclamptic pregnancies as compared to normal pregnancies [Table-1]. This finding is in concurrence with the findings of Udainia $A$. et al [18], and Pretorius DH. et al [15], who had observed a similar increase in marginal cord insertion in pre-eclamptic pregnancies. M arginal cord insertion in a previous pregnancy increases the risk of velamentous cord insertion in the subsequent pregnancy and vice versa [11]. In the present study, the incidence of velamentous cord insertion was found in $1.43 \%$ placentae of pre-eclamptic pregnancies [Table-1]. This finding is in-line with the study of Udainia A. et al. [18], whereas, it differs with the observation of Monie IW, who reported much higher frequency $(15.3 \%)$ of velamentous cord insertions in pregnancy induced hypertension [25].

Abnormalities in the attachment of umbilical cord on placenta have been associated with a number of complications in pregnancy i.e. vasa previa, preterm labor $[14,26]$. Previous studies show the association between the abnormal cord insertion and fetal malformations [7, 25, 27]. Fetal malformations associated with abnormal cord insertion are esophageal atresia, spina bifida, trisomy 21 and congenital heart defect i.e. ventricular septum defect [7]. An abnormal cord insertion has also been implicated in the induction of hypertension and intrauterine growth restriction (IUGR) [11, 15, 28].

In the present study, we found that the mean fetal birth weight decreases, as the attachment of umbilical cord in the placenta shifts from central to the periphery [Fig-1]. This finding is 
Table 3: Comparison of distribution of umbilical cord insertion with previous studies in uncomplicated pregnancies.

\begin{tabular}{|c|c|c|c|c|c|}
\hline \multirow{2}{*}{ Author's } & \multirow{2}{*}{$\begin{array}{c}\text { Method of } \\
\text { study }\end{array}$} & \multicolumn{4}{|c|}{ Variations in umbilical cord insertions } \\
\cline { 3 - 6 } & & $\begin{array}{c}\text { Normal } \\
\text { (Central/Eccentric) }\end{array}$ & Marginal & Velamentous & Furcated \\
\hline Lakshmidevi CK. et al [19] & Gross study & $78 \%$ & $20 \%$ & $2 \%$ & - \\
\hline Reddy VM. et al [20] & Gross study & $75.45 \%$ & $16.36 \%$ & $0.90 \%$ & $7.27 \%$ \\
\hline Sepulveda W. et al [21] & Sonography & $92.02 \%$ & $7.20 \%$ & $0.75 \%$ & - \\
\hline Donald N. Di Salvo et al [22] & Sonography & $74.37 \%$ & $22.22 \%$ & $7.41 \%$ & - \\
\hline Present study & Gross study & $87.14 \%$ & $12.86 \%$ & - & - \\
\hline
\end{tabular}

in concurrence with the study done by Udainia A. et al [18]. We found that abnormal cord insertion was significantly associated with low fetal birth weight [Table -2]. This finding is consistent with those reported by earlier observers [18, 24]. The vessels density is lower in placentae with abnormal cord insertion as compared to those with normal cord insertion, and the fetal stem vessels may be longer in the abnormal cord insertion, which would increase vascular resistance $[29,30]$. Therefore, abnormal cord insertion hampers the nutrient transfer to the fetus and may induce fetal growth restriction. Since pregnancies complicated with abnormal cord insertions are at great risk for adverse perinatal outcome, thus various investigators have suggested that the systemic identification of the abnormal cord insertion is an extremely important part of the prenatal sonographic evaluation [15, 21, 22].

\section{CONCLUSION}

Abnormalities in the development and site of insertion of umbilical cord have potential to affect fetal health and well-being. Abnormal insertions of umbilical cords are significantly associated with pre-eclampsia and these anomalous cord insertions are also significantly associated with low fetal birth weight. Mean fetal birth weight decreases, as the site of insertion of umbilical cord moves towards the periphery. Abnormal cord insertion increases the risk of intrapartum death at term, due to rupture of the unprotected umbilical vessels during labor. Therefore, prenatal sonographic detection of abnormal cord insertion might offer enough information to justify an increased focus throughout gestation and prompt additional care during and after labor.

\section{Conflicts of Interests: None}

\section{REFERENCES}

[1]. Kalkunte S, Padbury JF, Sharma S. Immunologic basis of placental function and disease: The placenta, Fetal membranes and Umbilical cord. In: Gleason C.A, Devaskar S.U, eds. Avery's Diseases of the Newborn. $9^{\text {th }}$ ed. Elsevier saunders Philadelphia; 2012: 50.

[2]. Tantbirojn P, Saleemuddin A, Sirois K, Crum CP, Boyd TK, Tworoger S, Parast M M . Gross abnormalities of the umbilical cord: related placental histology and clinical significance. Placenta. 2009 Dec 31;30(12):1083-88.

[3]. Cunningham FG, Leveno KL, Bloom SL, Hauth JC. Williams Obstetrics. 22 ${ }^{\text {nd }}$ ed. M cGraw-Hill; 2005:62027.

[4]. Liu CC, Pretorius DH, Scioscia AL, Hull AD. Sonographic Prenatal Diagnosis of Marginal Placental Cord Insertion Clinical Importance. Journal of ultrasound in medicine. 2002 Jun 1;21(6):627-32.

[5]. Kouyoumdjian A. Velamentous insertion of the umbilical cord. Obstetrics \& Gynecology. 1980 Dec 1;56(6):737-42.

[6]. Singh I and Pal GP. Human Embryology. 8th ed. India, Macmillan Publishers India Ltd. 2009, pp59-75.

[7]. Robinson LK, Jones KL, Benirschke K. The nature of structural defects associated with velamentous and marginal insertion of the umbilical cord. American journal of obstetrics and gynecology. 1983 May 15;146(2):191-93.

[8]. Hertig AT, Shea SM . Human Trophoblast: Normal and Abnormal: A Plea for the Study of the Normal so as to Understand the Abnormal Ward Burdick Award Address. American journal of clinical pathology. 1967 Mar 1;47(3):249-68.

[9]. Rolschau J. The relationship between some disorders of the umbilical cord and intrauterine growth retardation. Acta obstetricia et gynecologica Scandinavica. Supplement. 1977 Dec;72:15-21.

[10]. Heinonen S, Ryynänen M, Kirkinen P, Saarikoski S. Perinatal diagnostic evaluation of velamentous umbilical cord insertion: clinical, Doppler, and ultrasonic findings. Obstetrics \& Gynecology. 1996 Jan 31;87(1):112-7. 
[11]. Ebbing C, Kiserud T, Johnsen SL, Albrechtsen S, Rasmussen S. Prevalence, risk factors and outcomes of velamentous and marginal cord insertions: a population-based study of 634,741 pregnancies. PLoS One. 2013 Jul 30;8(7):e70380. Available at http://dx.doi.org/10.1371/journal.pone. 0070380.

[12]. Itskovitz JO, LaGamma EF, Rudolph AM . Effects of cord compression on fetal blood flow distribution and 02 delivery. American Journal of PhysiologyHeart and Circulatory Physiology. 1987 Jan 1;252(1):H100-9.

[13]. Soifer S), Kaslow D, Roman C, Heymann M A. Umbilical cord compression produces pulmonary hypertension in newborn lambs: a model to study the pathophysiology of persistent pulmonary hypertension in the newborn. Journal of developmental physiology. 1987 Jun;9(3):239-52.

[14]. Brody S, Frenkel DA. M arginal insertion of the cord and premature labor. American journal of obstetrics and gynecology. 1953 Jun 30; 65(6):1305-12.

[15]. Pretorius DH, Chau C, Poeltler DM, Mendoza A, Catanzarite VA, Hollenbach KA. Placental cord insertion visualization with prenatal ultrasonography. Journal of ultrasound in medicine. 1996 Aug 1;15(8):585-93.

[16]. Hasegawa J, Matsuoka R, Ichizuka K, Sekizawa A, Farina A, Okai T. Velamentous cord insertion into the lower third of the uterus is associated with intrapartum fetal heart rate abnormalities. Ultrasound in obstetrics \& gynecology. $2006 \mathrm{Apr}$ 1;27(4):425-9.

[17]. Park K. Park's textbook of Preventive and Social Medicine. 22nd ed. Jabalpur: M/S Banarsidas Bhanot India; 2013.

[18]. Udainia A, M ehta CD, Chauhan K, Suthar K, Chauhan $K$. Relation between umbilical cord insertion and foetal outcome in pregnancy induced hypertension. International Journal of Basic and Applied Medical Sciences. 2014 Jan;4(1):332-7. Available at http:// www.cibtech.org/jms.htm.

[19]. Lakshmi devi CK, Neelam S, Raghupathy NS. Morphological studies of normal human placenta at different gestational periods. IOSR- Journal of dental and medical sciences. 2013 May;6(3):9-15.

[20]. Reddy VM, Geetha SP, Nim VK. Variations in Placental attachment of umbilical cord. Journal of Anat. Soc. of India. 2012 Jun 1;61(1):1-4.
[21]. Sepulveda W, Wong AE, Gomez L, Alcalde JL. Improving sonographic evaluation of the umbilical cord at the second-trimester anatomy scan. Journal of Ultrasound in Medicine. 2009 Jun 1;28(6):831-5.

[22]. Di Salvo DN, Benson CB, Laing FC, Brown DL, Frates MC, Doubilet PM. Sonographic evaluation of the placental cord insertion site. AJR. American journal of roentgenology. $1998 \mathrm{M}$ ay; 170(5):1295-8.

[23]. Benirschke K. Abnormalities of the human placenta. NeoReviews. 2005 Sep 1; 6(9):e414-23.

[24]. Rath G, Garg K, Sood M. Insertion of umbilical cord on the placenta in hypertensive mother. J Anat Soc India., 2000;49(2):149-52.

[25]. Monie IW. Velamentous insertion of the cord in early pregnancy. American journal of obstetrics and gynecology. 1965 Sep 15;93(2):276-81.

[26]. Paavonen J, Jouttunpaa K, Kangasluoma P, Aro P, Heinonen PK. Velamentous insertion of the umbilical cord and vasa previa. International Journal of Gynecology \& Obstetrics. 1984 Jun 30;22(3):20711.

[27]. Raisanen S, Georgiadis L, Harju M, Keski-Nisula L, Heinonen $S$. Risk factors and adverse pregnancy outcomes among births affected by velamentous umbilical cord insertion: a retrospective population-based register study. European Journal of Obstetrics \& Gynecology and Reproductive Biology. 2012;165(2):231-4.

[28]. Cai LY, Izumi Sl, Koido S, Uchida N, Suzuki T, Matsubayashi H, Sugi T, Shida N, Kikuchi K, Yoshikata K. Abnormal placental cord insertion may induce intrauterine growth restriction in IVF-twin pregnancies. Human Reproduction. 2006 May 1;21(5):1285-90.

[29]. Misra DP, Salafia CM, Miller RK, Charles AK. Nonlinear and gender-specific relationships among placental growth measuresand the fetoplacental weight ratio. Placenta. 2009 Dec 31;30(12):1052-7.

[30]. Salafia CM , Zhang J, M iller RK, Charles AK, Shrout P, Sun W. Placental growth patterns affect birth weight for given placental weight. Birth Defects Research Part A: clinical and molecular teratology. 2007 Apr $1 ; 79(4): 281-8$.

How to cite this article:

Ankit Jain, Sonia Baweja, Rashmi Jain. STUDY OF THE PLACENTAL

ATTACHM ENT OF FUNICULUSUM BILICALISIN NORM AL AND PRE-

ECLAM PTIC PREGNANCIES AND ITS EFFECTS ON BIRTH WEIGHT.

Int J Anat Res 2017;5(1):3535-3540. DOI: 10.16965/ijar.2017.107 